\title{
Canine and feline obesity: a review of pathophysiology, epidemiology, and clinical management
}

This article was published in the following Dove Press journal:

Veterinary Medicine: Research and Reports

30 December 2014

Number of times this article has been viewed

\author{
John P Loftus \\ Joseph J Wakshlag \\ Cornell University College of \\ Veterinary Medicine, Veterinary \\ Medical Center, Ithaca, NY, USA
}

Correspondence: Joseph J Wakshlag Cornell University College of Veterinary Medicine, Veterinary Medical Center

I-I 20, Ithaca, NY I 4853, USA

$\mathrm{Tel}+\mathrm{I} 6072534389$

Fax +I 6072533534

Email jw37@cornell.edu

\begin{abstract}
Canine and feline obesity rates have reached pandemic proportions and are similar to those in humans, with approximately $30 \%-40 \%$ of dogs and cats being overweight to obese. Obesity has been associated with other health problems, including osteoarthritis, renal disease, skin disease, insulin resistance, and neoplasia in dogs, while in cats obesity is associated with dermatological issues, diabetes mellitus, neoplasia, and urolithiasis. The health issues appear to be slightly different across the two species, which may be due to some inherent differences in the hormonal milieu involved in obesity that differs between the dog and the cat. In this review, we discuss the complicated nature of the pathogenesis of obesity, the hormonal stimulus for orexigenic and anorexigenic behavior, adipose tissue as an endocrine organ, and most importantly, clinical management of the number one disease in canine and feline medicine.
\end{abstract}

Keywords: obesity, canine, feline, veterinary

\section{Pathophysiology of obesity}

The reasons for obesity are not completely evident as there are many different variables involved in its development. ${ }^{1-3}$ which has reached pandemic proportions in our pet populations. The major factors involved can be divided into factors that affect energy metabolism and those that affect energy intake and assimilation. Energy metabolism is directly affected by resting metabolic rate, active metabolic rate, and relative activity. Energy intake is affected by behavioral eating/feeding (hormonal and behavioral), digestion efficiency, and factors in food that affect nutrient assimilation. ${ }^{4}$ For many years, it was thought that obesity could be explained by a glucostatic model or a lipostatic model. ${ }^{5}$ These two models suggested that either glucose or lipid in the diet were the major drivers behind appetite generation and suppression through the hormonal milieu that occurs through ingestion of these substrates. Over time, these theories have been shown to have some validity, but cannot be separated, with possible involvement of both substrates and potentially other factors. Another prevalent theory, ie, the set-point theory, assumes that there is control of eating based on an energy set-point that slowly maladjusts. The rationale behind this theory is that most humans will reach an adult weight, and this adult weight will only vary by $10 \%$ higher or lower for a majority of the adult lifespan. ${ }^{5}$ Part of this rationale is that a small incremental increase of 100 kilocalories a day will lead to obesity and continued weight gain. This theory cannot be fully supported when one realizes that fat is a metabolic tissue with weight gain and that new lean tissue deposition has to support the new adipose tissue. Therefore, the extra 100 kilocalorie increase will be adjusted for at some point during the deposition of adipose and lean tissue., ${ }^{4,5}$ 
The glucostatic theory suggests that the primary genesis of hunger is via serum glucose homeostasis and the hormones that regulate this, including insulin. It has been shown that glucose and other glucostatic hormones (amylin and glucagon-like peptide-1 [GLP-1]) not only drive insulin secretion but also drive the hunger centers in the brain. ${ }^{5}$ This theory has lost favor for the lipostatic model (not to be confused with the adipostatic model that will be described later when discussing leptin) since it appears that fatty acid in the diet is the primary driving factor for increasing gastrointestinal hormone secretion that feeds back to the appetite centers in the brain to either increase or decrease orexigenic behaviors. ${ }^{5,6}$

\section{Appetite centers}

Current knowledge of the appetite centers in the brain show that eating behavior is driven by two sets of neurons near the hypothalamic centers cranially to the hypothalamus along the median eminence adjacent to the third ventricle of the brain, called the arcuate nucleus. The arcuate nucleus has two nuclei that run adjacent to one another and contain the preproopiomelanocortin/cocaine amphetamine related transcript (POMC-CART) neurons and the neuropeptide Y/agouti-related protein (NPY-AGRP) neurons. The POMC-CART neurons when stimulated will activate the hypothalamic feeding centers, primarily the dorsomedial, paraventricular, and lateral hypothalamic nuclei, through release of orexins and melanocortin to stimulate these areas that diminish appetite. ${ }^{6-8}$ The same areas of the brain are stimulated by the NPY-AGRP neurons to increase eating behavior. In addition to these major pathways, the medulla also contains neuronal tracts that help diminish appetite, called the nucleus tractus solitaris ${ }^{6-8}$ (see Figure 1). This pathway appears to be stimulated by hormones from the gastrointestinal tract, such as cholecystokinin, as a quick vagal hunger break soon after eating, which is short-lived. ${ }^{6}$ In addition to cholecystokinin, rises in insulin occur after ingesting a meal, which also affects the arcuate nucleus by stimulating the POMC-CART neurons and slowing firing of the NPY-AGRP neurons to diminish appetite. ${ }^{6-8}$ Although these could be interesting targets to examine for pharmacological intervention, the vast organismal effects of both these hormones in pancreatic secretion and glucose regulation preclude them as viable pharmacological targets.

Two very interesting hormones that are released from the gastrointestinal tract and have some potential for pharmacological intervention are peptide YY (PYY) and GLP-1. Both GLP-1 and PYY are produced and secreted by the L cells of the distal jejunum and ileum. L cells act as nutrient sensors,

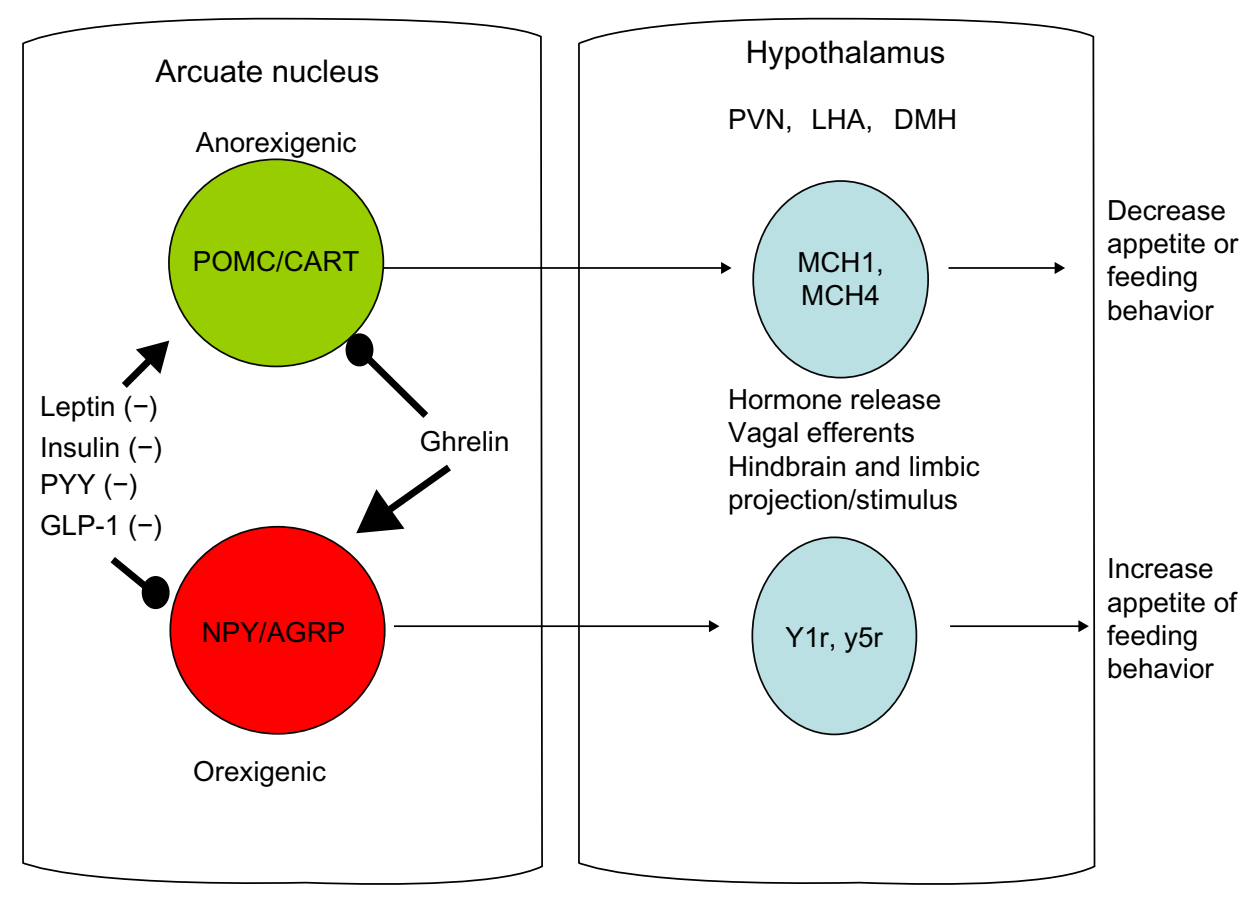

Figure I Schematic showing involvement of the arcuate nucleus and hypothalamus in eating behavior.

Abbreviations: POMC-CART, preproopiomelanocortin cocaine amphetamine transcripts; NPY-AGRP, neuropeptide Y-agouti related peptide; MCH, melanin-concentrating hormone; YIr, y5r, neuropeptide Y receptor I and 5; PVN, paraventricular nucleus; DMH, dorsomedial hypothalamus; LHA, lateral hypothalamic area; PYY, peptide YY; GLP-I, glucagon-like peptide I. 
and when simulated, primarily by fatty acids, they produce both PYY and GLP-1. ${ }^{9-11}$ The influence of these hormones is highlighted by recent findings of heightened GLP-1 and PYY secretion in experimental procedures such as certain gastric bypass surgeries and sleeve gastrectomy, whereby delivery of nutrients to distal parts of the gastrointestinal tract alters appetite and insulin sensitivity. ${ }^{9-11}$

When GLP-1 is released into the blood stream, it induces arcuate nucleus stimulation of the POMC-CART neurons and reciprocal inhibition of the NPY-AGRP neurons, breaking hunger. GLP-1 also has insulin-sensitizing effects and can be found as a synthetic analog for use in prediabetic human patients to improve insulin sensitivity with the added benefit of causing modest satiety. ${ }^{10}$ The effects can last for up to 12 hours, making it a viable pharmacological target. Although used in human medicine already, one of the problems is resistance to the drug at the level of the peripheral tissues and the hypothalamus, requiring adjustment of dosing for effect. Patients also experience lethargy and malaise induced by GLP-1 as a negative side effect. ${ }^{12}$

PYY, on the other hand, may have more potential since it has a similar duration of effect as GLP-1, with fewer and less severe side effects. PYY is released from L cells when fatty acids are absorbed..$^{911}$ Once released, it too acts to stimulate the POMC-CART neurons and diminish NPY-AGRP signaling, thereby breaking hunger. However, as with GLP-1, adjustment of dosing due to hypothalamic tolerance seems to be an issue. ${ }^{13}$

All of the aforementioned hormones are anorexigens, and the only orexigenic hormone is ghrelin. Ghrelin is a hormone that is released from the neuroendocrine cells interspersed along the epithelium in the fundus of the stomach, and appears to act counter to PYY and GLP-1 by stimulating hunger through excitation of the NPY-AGRP neurons. ${ }^{6,14}$ Ghrelin secretion tends to be highest when the stomach is empty and diminishes when the stomach is stretched and nutrient stimulus occurs. ${ }^{6,14}$ Ghrelin's halflife is short and it is not active as a native peptide alone, in that it needs to be post-transitionally modified for activity at the hypothalamus. Ghrelin must be octenylated at serine residue 3 through ghrelin octenylation acyl transferase. ${ }^{6,14}$ Considering the circuitous nature of its activity and formation, pharmacological inhibition has been sought with little success, primarily due to ghrelin's negative side effect of inducing growth hormone release. ${ }^{15}$ However, in elderly populations, its appetite stimulating and growth hormone enhancing properties may be beneficial, and agonists are currently in clinical trials. ${ }^{16}$
Dogs and cats are assumed to have similar signaling mechanisms to control appetite. There is evidence that dogs are sensitive to PYY clinically. Dirlotapide, a canine obesity drug, appears to work by inhibiting fatty acid absorption, causing a rise in serum PYY as the primary mechanism for decreasing appetite (Personal communication, Dr A Hickman, Pfizer Pharmaceuticals). Much like Victoza ${ }^{\circledR}$ for humans (GLP-1 analog), the dosing of dirlotapide requires adjustment due to hypothalamic receptor downregulation, making hunger difficult to manage. ${ }^{17}$

\section{Fat as an endocrine organ}

By the 1950s, it was already established that there was a hormonal system in place to break hunger, but the mechanisms involved were unknown. Jackson Laboratories had developed strains of mice that gained excessive body weight and were thought to have mutations that led to obesity, generating excitement that obesity was genetically controlled and thereby potentially curable. Interest was heightened when these two mouse strains, which were morbidly obese, had their blood supplies fused surgically in parabiosis models with normal mice. One strain of obese mice when joined to a normal mouse made the normal mouse lose weight and slowed eating, while the other obese mouse strain lost weight when fused with the normal mouse. ${ }^{18,19}$ This suggested that one mouse had a mutation in a hormone, while the other had a mutation in the receptor for that hormone. It was not until 1994 that the hormone receptor system was identified to be leptin. ${ }^{20}$

Leptin is one of the hormones released in relatively large quantities from adipose tissue. It is actually a cytokine-like hormone that acts at the level of the arcuate nucleus to break hunger by stimulation of POMC-CART neurons. It has potent effects, and for many years was thought to be the ideal pharmacological target to help control the obesity epidemic. ${ }^{19,20}$ Unfortunately, clinical trials using synthetic leptin that, although useful, induced side effects due to immunological reactions and resistance, leading to poor clinical utility. ${ }^{21}$ Synthetic mimetics also proved limiting, as resistance to the drugs occurred and dosing issues were problematic. ${ }^{21,22}$ In dogs and cats, one of the universal similarities with humans and rodents is that plasma leptin strongly correlates with obesity, which has led to much controversy about an adipostatic theory of obesity. This theory has been debunked due to the inability of leptin or leptin analogs to control satiety, as leptin seems to be short in its duration of action, and more potent satiety is produced by gastrointestinally released hormones like GLP-1 and PYY. ${ }^{23,24}$ 
Over the last 10 years, there have been over 100 different proteins, peptides, and cytokines discovered that are released from fat tissue, so the idea that fat is an inert triglyceridestoring tissue has long passed. In obese animals, from a histological perspective, it is common to find areas of adipocyte necrosis and infiltration of inflammatory cells. These areas of necrosis are thought to be part of the inflammation of obesity that leads to "metabolic syndrome" in people. ${ }^{25,26}$ The syndrome is associated with increased risk of many diseases, including diabetes mellitus type 2, hypertension, and atherosclerosis. This inflammation is driven by the release of cytokines including interleukin (IL)-1 $\beta$, tumor necrosis factor alpha, IL-6, and IL-8. The cytokines of primary interest are locally released adipose tumor necrosis factor alpha and systemically increased IL- $6 .^{25,26}$ In addition, stimulated adipocytes release a hormone called resistin, which creates cross-talk with local macrophages to induce heightened cytokine secretion. ${ }^{24,25}$ Adipocytes also secrete small amounts of C-reactive protein (CRP) and cytokines released from adipose tissue also stimulate the liver to synthesize and secrete CRP. ${ }^{24}$ CRP has become the primary marker for chronic inflammation in humans and dogs. ${ }^{24}$

In lean dogs, plasma CRP is usually below $5 \mu \mathrm{g} / \mathrm{mL}$, while in chronic obesity plasma CRP has been shown to be around 5-15 $\mu \mathrm{g} / \mathrm{mL}$. However, some dog studies suggest that CRP decreases during weight loss, while other studies show that CRP appears to be unchanged..$^{24,27-30}$ There has been no consensus regarding use of CRP as a marker in obesity due to conflicting results, unlike in people where CRP elevations are directly correlated with the risk of cardiovascular disease and diabetes as part of the metabolic syndrome. ${ }^{31}$ Cats do not make CRP as part of the inflammatory response, and other markers are used to assess chronic inflammation in cats. ${ }^{32}$ Even in cats, there is conflicting evidence that acute phase proteins like serum amyloid A decrease after weight loss or increase during weight gain. ${ }^{24}$

The most widely studied and interesting adipose tissue-derived hormone from a comparative perspective is adiponectin. Adiponectin is not a cytokine-derived hormone, but rather an insulin-sensitizing hormone that is present at very high concentrations in the bloodstream. Adiponectin concentrations are highest in lean individuals and lowest in obese people, and are therefore reciprocal to leptin release. Its synthesis and release are complicated in that the adiponectin monomer is approximately $30 \mathrm{kDa}$ and has limited insulin-sensitizing effects; however, when synthesized, the endoplasmic reticulum will aggregate three monomers as a trimer through disulfide linkages. Larger aggregates are also assembled as hexamers, which are considered to be the low molecular weight forms of adiponectin. High molecular weight forms are also secreted as octadecamers (18 monomers), which appear to have the most potent insulinsensitizing effects of all the forms found in the bloodstream. ${ }^{33}$ During weight loss in patients who have had bariatric surgery, one of the first hormonal changes that occurs is synthesis of more octadecamers, which is associated with improved insulin sensitization. ${ }^{34}$ In cats, adiponectin is formed and there have been associations with decreasing adipose tissue and increased adiponectin secretion. However, in dogs, the trend of adiponectin secretion and adiposity does not follow the human paradigm. Dogs appear to have robust adiponectin secretion whereby, regardless of obesity, serum concentrations average around $20-30 \mu \mathrm{g} / \mathrm{mL},{ }^{24,33,35}$ while in cats and humans the concentrations are around 5-10 $\mu \mathrm{g} / \mathrm{dL}$ and increase in lean cats to around $20-30 \mu \mathrm{g} / \mathrm{dL} .{ }^{36}$ Adiposity does not appear to effect adiponectin secretion in dogs, although one study identified a small subset of dogs with obesity that may have diminished adiponectin, and these dogs may also display insulin resistance..$^{28,29,37,38}$ Some of these discrepancies may be due to the effects of other hormones on adiponectin secretion, such as testosterone and thyroxine, which have negative effects on adiponectin secretion. ${ }^{39}$ In addition, the high molecular weight that should resolve above $>360 \mathrm{kDa}$ on nondenaturing gel electrophoresis cannot be found in dogs when compared with cats, cows, horses, and humans, suggesting more comparative differences (authors' unpublished data). ${ }^{35}$ It has been hypothesized that the subtle differences in dogs might be the reason why type 2 diabetes is not as prevalent in dogs, and identification of a true metabolic syndrome in dogs has eluded investigators.

Cats, on the other hand, show obesity-related metabolic dysfunction that some suggest is similar to metabolic syndrome in humans, whereby correction of obesity leads to improved insulin sensitivity. ${ }^{40}$ Again, cats may not follow the same physiological paradigm as humans and rodents with regard to their adipose tissue response to obesity. In humans and rodents, the visceral fat surrounding the splanchnic organs is the primary depot for a majority of the adipokines secreted, including adiponectin. Studies in cats appear to be different in that subcutaneous adipose tissue is the largest contributor to the adipokine response. ${ }^{41}$

What is evident is that our understanding of the response to obesity in dogs and cats is in its infancy, and what occurs in naturally occurring clinical obesity could be different from what occurs in laboratory models of rapid weight gain and weight loss. ${ }^{42}$ In the authors' opinion, the study of naturally 
occurring obesity in the sentinel population of dogs and cats living among us may be a better clinical model than what is being created in many rodent models in laboratories around the world. Some of the inherent species differences may not fit the rodent or human models precisely, but deserve attention since the differences in species may underpin our understanding of the pathogenesis of associated diseases like diabetes.

\section{Epidemiology and clinical treatment of obesity}

The reported prevalence of overweight/obesity in dogs has ranged from $34 \%$ to $53 \%$ in the USA during the past decade. ${ }^{43}$ Similar rates have been reported in other developed countries, including France, Australia, and the UK, where rates reported by veterinary professionals were $38.8 \%$, $41 \%$, and $52 \%$, respectively. ${ }^{44}$ Figures as high as $38.9 \%$ for overweight and $20.4 \%$ for obesity have been reported more recently. ${ }^{44}$ Similarly, the prevalence of obesity in cats is reported to range from as low as $6 \%$ to as high as $44 \%$ in one review, although more recent reports identify feline overweight/obesity to be as low as $11.5 \%$ in the UK. ${ }^{45,46}$ The increasing rates of obesity in small animals over the past 20-30 years has occurred in parallel with the rising epidemic of obesity in the human population. ${ }^{47}$ Interestingly, this increase in obesity has also been documented in both research and feral animal populations, suggesting the possibility of unidentified obesity-promoting factors that affect all of these populations in concert. ${ }^{47}$ While there has been a well documented association between obesity in dogs and in their owners, ${ }^{48-50}$ the same is not true for cats. In a study performed in the Netherlands, the body mass index of owners was compared with percent overweight in their pets. While there was a significant correlation between body mass index and percent overweight for dog owners and their dogs, regression analysis did not find a significant association between body mass index of cat owners and percent overweight in their cats. ${ }^{51}$ An important contributing factor to obesity in cats in one study was related to owner perception. In that study, underestimation of body condition by owners was the single most important risk factor for obesity in a cohort of cats based on an owner survey in New Zealand. ${ }^{52}$ This result also supports the concept that the failure of owners to recognize excess weight in their pets is an essential factor in persistence of an overweight or obese state in their animals. Other contributing factors include type of diet, socioeconomic status, owner lifestyle, pet activity, and pet body condition. However, perhaps the most consistently identified predisposing factor for obesity is neutering. Neutered dogs are more likely to be obese due to a decrease in maintenance energy requirement (MER) and increased food intake. ${ }^{53}$ However, age at neutering does not impact the risk of dogs becoming overweight, and neutering only increased the risk relative to intact dogs during the first 2 years after gonadectomy. ${ }^{43}$ What remains to be determined is whether this is a metabolic influence due to gonadectomy or a behavioral response resulting in less activity. In addition to lack of owner recognition, breed standards for a number of purebred dogs favor a slightly overweight condition that is borne out in the show dog population. ${ }^{54}$

\section{Understanding energy requirements}

Determination of energy requirements begins with estimating ideal body weight. Body condition score (BCS) provides an approximation of the extent to which an animal is overweight, so can be used to objectively determine ideal body weight. For every integer increase in BCS over 5 on a 9-point scale, an animal is estimated to increase in percentage overweight by $10 \%-15 \% .{ }^{54}$ For example, a $10 \mathrm{~kg}$ dog with a BCS of $7 / 9$ would be $20 \%-30 \%$ overweight. A BCS of $5 / 9$ has been correlated with approximately $15 \%-20 \%$ body fat in dogs and $25 \%-30 \%$ in cats. ${ }^{55-58}$ Whenever possible, energy calculations should be performed using ideal body weight in kilograms $\left(\mathrm{BW}_{\mathrm{kg}}\right)$. Two equations are available for estimating the resting energy requirement (RER) in companion animals. The metabolic or exponential equation, $70\left(\mathrm{BW}_{\mathrm{kg}}\right)^{0.75}$, is the preferred method and is appropriate for patients of all body weights, while the second linear equation, ie, $70+30\left(\mathrm{BW}_{\mathrm{kg}}\right)$, is only accurate for animals weighing more than $2 \mathrm{~kg}$ and less than $30 \mathrm{~kg} .{ }^{59}$ Once RER is calculated, an MER factor may or may not be applied. In the case of the obesity-prone dog or cat, no MER factor is typically applied. In contrast, the animal not prone to obesity should have an appropriate MER applied. ${ }^{59}$ In the experience of the authors, an MER of 1.2-1.4× RER is generally acceptable for the average house dog; however, highly active intact dogs may require an MER of 1.8-2× RER. Dogs and cats generally differ in their energy requirements, as discussed below (Table 1 ).

The energy requirements for dogs have been shown to vary significantly depending on a multitude of factors. In fact, energy requirements can differ substantially even between breeds of similarly sized small dogs. ${ }^{60}$ The breeds with energy requirements not well predicted by general energy equations include the Newfoundland, Great Dane, and terriers. ${ }^{61}$ MERs for dogs range from 94 to $250 \mathrm{kcal}$ 
metabolizable energy $(\mathrm{ME}) \times \mathrm{kg} \mathrm{BW} \mathrm{B}^{0.75} \cdot{ }^{59}$ Thus, it is important to be cognizant of the influence of breed, age, and activity on energy requirements when conceiving a patient-tailored weight loss program.

The MER of the typical indoor neutered cat is similar to the RER. Equations in the most recent National Research Council guideline provide an estimate of energy requirements for lean cats as $100 \mathrm{kcal} \mathrm{ME} \times \mathrm{BW}(\mathrm{kg})^{0.67}$. The energy requirements for overweight or obese cats $(\mathrm{BCS}>5 / 9)$ are estimated to be $130 \mathrm{kcal} \times \mathrm{BW}(\mathrm{kg})^{0.4}$ (Table 1). ${ }^{59} \mathrm{BMR}$ has been measured in the cat; however, accurate measurement is precluded by a host of factors that are discussed elsewhere. ${ }^{59,61}$ Recently, basal metabolic rate in the face of weight loss complemented by carnitine supplementation has been measured in the cat. In this study, the daily energy expenditure of cats was $69-96 \mathrm{kcal} / \mathrm{kg} /$ day on a lean body mass basis. ${ }^{61}$

\section{Weight loss protocols}

Recognition of the overweight or obese cat or dog is the first step for any weight loss protocol. Guidelines for nutritional assessment published by the World Small Animal Veterinary Association and American Animal Hospital Association reflect an increasing recognition of the importance of nutrition in clinical practice. ${ }^{62-64}$ Once the need for weight loss in the patient is recognized, caloric restriction can be implemented according to calculation of RER based on ideal body weight and is the mainstay of any weight loss program.

Table I Maintenance energy requirements based on linear or exponential equations for dogs and cats based on lifestyle and activity status

\begin{tabular}{|c|c|c|c|}
\hline $\begin{array}{l}\text { Dog } \\
\text { lifestage }\end{array}$ & $\begin{array}{l}\text { MER } \\
\text { (kcal ME/D) }\end{array}$ & $\begin{array}{l}\text { Cat } \\
\text { lifestage }\end{array}$ & $\begin{array}{l}\text { MER } \\
\text { (kcal ME/D) }\end{array}$ \\
\hline Active intact & $1.8\left(30 * \mathrm{BW}_{\mathrm{kg}}+70\right)$ & Active intact & $1.4\left(30 * \mathrm{BW}_{\mathrm{kg}}+70\right)$ \\
\hline $\begin{array}{l}\text { Active } \\
\text { neutered }\end{array}$ & $1.6\left(30 * \mathrm{BW}_{\mathrm{kg}}+70\right)$ & $\begin{array}{l}\text { Active } \\
\text { neutered }\end{array}$ & $1.2\left(30 * \mathrm{BW}_{\mathrm{kg}}+70\right)$ \\
\hline $\begin{array}{l}\text { Inactive } \\
\text { neutered }\end{array}$ & $1.2\left(30 * \mathrm{BW}_{\mathrm{kg}}+70\right)$ & $\begin{array}{l}\text { Inactive } \\
\text { neutered }\end{array}$ & $1.0\left(30 * \mathrm{BW}_{\mathrm{kg}}+70\right)$ \\
\hline $\begin{array}{l}\text { Obesity } \\
\text { prone }\end{array}$ & I.I $\left(30 * \mathrm{BW}_{\mathrm{kg}}+70\right)$ & $\begin{array}{l}\text { Obesity } \\
\text { prone }\end{array}$ & $\begin{array}{l}0.9-1.0 \\
\left(30 * \mathrm{BW}_{\mathrm{kg}}+70\right)\end{array}$ \\
\hline Active intact & $130\left(\mathrm{BW}_{\mathrm{kg}}\right)^{0.75}$ & Active intact & $100\left(\mathrm{BW}_{\mathrm{kg}}\right)^{0.67}$ \\
\hline $\begin{array}{l}\text { Active } \\
\text { neutered }\end{array}$ & $110\left(\mathrm{BW}_{\mathrm{kg}}\right)^{0.75}$ & $\begin{array}{l}\text { Active } \\
\text { neutered }\end{array}$ & $90\left(\mathrm{BW}_{\mathrm{kg}}\right)^{0.67}$ \\
\hline $\begin{array}{l}\text { Inactive } \\
\text { neutered }\end{array}$ & $100\left(\mathrm{BW}_{\mathrm{kg}}\right)^{0.75}$ & $\begin{array}{l}\text { Inactive } \\
\text { neutered }\end{array}$ & $75\left(\mathrm{BW}_{\mathrm{kg}}\right)^{0.67}$ \\
\hline Obesity prone & $95\left(\mathrm{BW}_{\mathrm{kg}}\right)^{0.75}$ & Obesity prone & I $30\left(\mathrm{BW}_{\mathrm{kg}}\right)^{0.4}$ \\
\hline
\end{tabular}

Note: Reprinted with permission from the National Academies Press, Copyright (C) 2006, National Academy of Sciences. ${ }^{114}$

Abbreviations: $\mathrm{D}$, day; $\mathrm{ME}$, metabolizable energy; $\mathrm{BW}_{\mathrm{kg}}$, body weight in $\mathrm{kg}$; MER, maintenance energy requirement.
Determining caloric restriction in dogs requires a thorough diet history, which should include an evaluation of the patient's activity level to determine if restriction is to be based on RER or MER as described above. Once this has been established, the daily calories provided should be $60 \%-70 \%$ of this value to achieve a safe rate of weight loss. In cats, concerns about the potential to induce hepatic lipidosis during caloric restriction lead many clinicians to choose a more conservative caloric restriction (70\%) in the overweight cat.

Many diet options are available for weight loss. The most convenient and effective diet is often a veterinary therapeutic weight loss diet. These diets provide a number of benefits over other over-the-counter diets with respect to substrate balance. In a comparison of five diets ranging from a high energy over-the-counter product to a therapeutic ultra weight loss diet, the therapeutic diets had fewer nutrients falling below the National Research Council minimum than did over-the-counter products when fed for weight loss. ${ }^{65}$ In this report and a subsequent study, choline and selenium were consistently the nutrients of concern in the face of caloric restriction; however, the clinical significance of this is not clear. ${ }^{55,65}$ Many of the therapeutic diets are lower in caloric density and can help enhance gastric filling and thus shortterm satiety. As many owners equate begging and other signs of hunger as indicators of malnourishment, improving satiety generally results in greater owner compliance, in the authors' experience.

An important component of an effective weight loss program is anticipating obstacles that the practitioner or the owner will encounter through the process. The provision of treats in the diet can be a significant source of calories for some dogs and cats. Incorporating treats into a weight loss plan helps provide specific guidelines for owners. It is generally recommended that treats comprise $10 \%$ of the total dietary calories. Owners often feel that treats are an important contributor to the bond with their pet, so providing a treat allowance will likely improve compliance. ${ }^{66}$ The use of canned food or soaked dry food may provide a satiety advantage over kibble dry due to enhanced gastric fill. ${ }^{67}$ Establishing monthly rechecks with the client will provide the ability to alter the weight loss protocol as needed based on the patient's actual weight trends vis-à-vis weight loss goals and help maintain owner motivation. ${ }^{68,69}$

Although there is a relative paucity of studies documenting the benefits of weight loss in companion animals compared with humans, there are data to support exercise as a part of a weight loss protocol. ${ }^{55,70,71}$ In humans, a number of benefits 
from exercise with respect to weight loss have been identified, and include stimulation of lipid versus carbohydrate oxidation, increased energy expenditure, maintenance of lean body mass, an increase in basal metabolic rate during caloric restriction, and other potential physiological effects. ${ }^{72}$ A major obstacle to realizing the benefits of exercise in companion animal weight loss protocols is owner compliance. Dogs enrolled in a weight loss program were monitored for activity by way of a validated pedometer system. When inactive versus active cohorts stratified by basal activity level were followed through a weight loss program that included encouraging increased activity, activity did not significantly increase over the course of the study. ${ }^{70}$ Thus, despite recommendations for increased exercise, owners will not necessarily comply by increasing their pet's activity during a weight loss program. In contrast, pet owners who were themselves overweight or obese were enrolled in a dual exercise program. This study found that two thirds of the owner activity occurred with their dogs. ${ }^{73}$ Exercise protocols for weight loss in cats have not been appropriately evaluated. Interestingly, mild caloric restriction in the form of a wet food resulted in increased activity of cats in a colony situation. This was likely attributable to food-seeking behavior. ${ }^{74}$ Ultimately, while increasing activity is recommended as part of weight loss protocols, it is unlikely that they provide a significant benefit in most indoor cats and owner compliance is an obstacle.

Resolution of the weight loss program occurs when the patient reaches their ideal weight. It is important to continue to monitor these patients for maintenance of their ideal weight. This is particularly true as most of these patients will be prone to obesity, and their energy requirements generally decrease following weight loss. ${ }^{75,76}$ Continuation of a veterinary weight loss diet may be appropriate for weight maintenance in obese-prone patients; however, this assumes the patient does not have conflicting nutritionally modifiable disease and that the food meets their appropriate lifestage maintenance requirement.

\section{Substrate balance Protein and weight loss}

Increased amounts of dietary protein benefit both cats and dogs during weight loss for a number of reasons. Perhaps the most straightforward benefit is the ability to meet dietary protein requirements in the face of caloric restriction. High protein diets help to maintain lean body mass during weight loss in dogs, cats, and humans. ${ }^{77-90}$ Another benefit of dietary protein is its thermic effect. That is, protein ingestion results in increased energy expenditure in contrast with equal calories consumed from fat or carbohydrate. ${ }^{81}$ High protein diets are more effective in weight loss management in pets while maintaining lean body mass better. ${ }^{77-82}$ The satiety effects of different protein sources have been evaluated, and there appears to be no advantage in any one protein source in this regard. ${ }^{83}$

\section{Fat, omega three fatty acids, and weight loss}

In general, dietary fat represents a challenge to any weight loss diet due to its high caloric density. For each gram of dietary fat ingested, 8.5-9 kcal are consumed. ${ }^{59}$ Thus, as dietary fat increases, so does the energy density of the diet. This results in smaller volumes of food needed on an isocaloric basis and a concomitant reduction in gastric fill, with higher fat diets typically resulting in reduced satiety. The composition of dietary fat, however, may actually have some beneficial effects in the context of weight loss.

In obesity, the production of mediators of inflammation derived from adipose tissue is increased. This includes both adipokines derived from adipocytes and cytokines produced by recruited macrophages. ${ }^{84}$ Diets enriched with omega-3 polyunsaturated fatty acids, particularly eicosapentaenoic acid and docosahexaenoic acid, can modulate lipid inflammatory mediators. The introduction of certain omega-3 polyunsaturated fatty acids into eicosanoid pathways results in production of inert prostanoids and leukotrienes that mitigate the proinflammatory signals from eicosanoids derived from arachidonic acid. Additionally, other effects of omega-3 polyunsaturated fatty acids appear to be exerted on adipocytes by decreasing adipokine production and induction of gene transcription. ${ }^{85,86}$ Omega- 3 fatty acids are potent peroxisome proliferation activation receptor agonists, and activation of peroxisome proliferation activation receptor gamma results in production of high molecular weight adiponectin. $^{87}$

\section{Carbohydrates and weight loss}

There is a popular conception that carbohydrates are anathema to a weight loss diet in people. While certain components of the rationale for this assertion do have a physiological basis (eg, stimulation of energy substrate storage by insulin), there are a number of reasons why carbohydrates are not a priori detrimental to a weight loss diet protocol. Firstly, the energy provided per gram of carbohydrate is essentially the same as that provided per gram of protein. ${ }^{59}$ Thus, in terms of energy density, the proportion of fat in the diet is the only energy substrate that will significantly affect overall energy density. Secondly, carbohydrates are considered 
protein-sparing. That is, when cellular energy requirements are met predominantly by carbohydrate sources, the protein substrate is preferentially utilized for protein synthesis and not for production of energy.

Increased amounts of dietary fiber are often incorporated into canine and feline diets designed for weight loss. This strategy is primarily utilized to increase satiety. Several studies have documented improved satiety in the context of canine weight loss diets. ${ }^{82,88,89}$ The general mechanisms proposed for dietary fiber-related weight loss include reduction in energy density of feed, increased chewing (unlikely to play a role in commercial pet food) and associated anorexigenic signals, increased gastric fill and a reduction in energy absorption from the diet. In the case of fermentable dietary fiber, stimulation of GLP-1 is enhanced, thus potentially promoting satiety. ${ }^{90}$

\section{Fiber and colonic energy}

Mounting evidence indicates that the influences of dietary fiber on the microbiota and microbial metabolism of the gut may play an important role in overweight and obese individuals. Short-chain fatty acids (SCFA) are produced by microbial fermentation of fiber. Different gut microbial species have differential capacities to produce SCFA from fermentable dietary fiber. ${ }^{91}$ In the case of people, energy derived from SCFA typically provides approximately $10 \%$ of an individual's energy requirements. However, the smaller relative colon volume in dogs, and even more so in cats, corresponds to a lower contribution of SCFA to energy in these species. ${ }^{59}$ An association between higher SCFA in obese versus lean animals has been established, suggesting a simple caloric excess from SCFA. ${ }^{92}$ The prebiotic source of fiber, oligofructose, favorably modifies the gut microbiota, produces SCFA that induce satiety-promoting factors and reduce body weight. Finally, SCFA have immunomodulatory effects that are beneficial in the face of obesity. ${ }^{90}$

\section{Supplements Isoflavones}

In humans, there are many documented or perceived health benefits from inclusion of soy in the diet. Benefits for weight loss have been documented by in vitro, animal, and human epidemiological studies. The soy isoflavone genistein is the best studied soy derivative in the context of weight loss and obesity. ${ }^{93}$ Treatment of adipocytes with genistein in vitro induces apoptosis and attenuates proliferation. ${ }^{94}$ However, the plasma and blood levels of genistein required may be difficult to achieve with the consumption of most soy products.
Although not all studies agree, obese mice and rats fed soy-based diets showed reduction in weight and adiposity, and when obese mice were injected with genistein, the mice showed a decrease in fat mass without decreased body weight compared with controls. ${ }^{95-97}$ Epidemiological studies in people have yielded largely inconsistent results. Overall, soy-based protein has not been shown to have a benefit over milk-based protein in humans. ${ }^{93}$ An interesting effect of a diet high in soy isoflavones in dogs was an elevation in total T4 concentrations. ${ }^{98}$ The diet did not induce a hyperthyroid state, but could promote a higher metabolic rate, thus facilitating weight loss. In neutered cats, soy isoflavone supplementation induced a short term loss of appetite that rebounded quickly after addition of genistein. More interestingly, the genisteinsupplemented cats continued to gain weight; however, the primary weight gain was lean mass, suggesting a physiological switch to lean mass accretion that is poorly understood and requires further research. ${ }^{99,100}$

\section{Carnitine}

Carnitine functions to promote shuttling of cytosolic longchain fatty acids across the mitochondrial membrane to promote their $\beta$-oxidation within the mitochondrial matrix. ${ }^{101}$ Peer-reviewed studies clearly documenting a benefit from L-carnitine supplementation in dogs are lacking. ${ }^{76,102}$ Carnitine supplementation was speculated to facilitate loss of adiposity while maintaining lean body mass in one study; however, the diet used was also high in protein and fiber with a low caloric density. ${ }^{76}$ Thus, it is difficult to assign a specific effect of carnitine in this study. In cats, L-carnitine supplementation has improved the rate of weight loss, as well as increased their basal energy requirements. ${ }^{61,103}$ Interestingly, L-carnitine infusions abrogated acidosis and ketosis in starved dogs and lipidotic cats. ${ }^{104,105}$

\section{Medium chain triglycerides}

Medium-chain triglycerides (MCT) are comprised of 6-12 carbons. The most common sources of high concentrations of MCT are coconut oil and palm oil. MCT are thought to enhance weight loss by virtue of their more efficient $\beta$-oxidation than long-chain triglycerides, as well as their lower caloric volume per gram of substrate $(8.3 \mathrm{kcal} / \mathrm{g})$. MCT can cross the mitochondrial membrane independent of the carnitine system. ${ }^{106}$ In rats, MCT have had favorable effects on satiety, energy expenditure, and brown fat thermogenesis. ${ }^{107-109}$ In dogs, they have been evaluated with respect to promoting ketosis and mitigating age-related changes, including dementia. ${ }^{110,111}$ 


\section{Other supplements}

Additional supplements have been investigated in the context of obesity and weight loss in companion animals. The effects of green tea extract supplementation were investigated in a canine model of obesity-induced insulin resistance. Dogs supplemented with green tea extract for 12 weeks at approximately $80 \mathrm{mg} / \mathrm{kg}$ had enhanced insulin sensitivity and decreased triglyceride levels. Gene expression of peroxisome proliferation activation receptor gamma, lipoprotein lipase, and adiponectin were all higher in both visceral and subcutaneous fat tissue of dogs supplemented with green tea extract. ${ }^{12}$ Obese cats supplemented with citrus bioflavonoids had decreased plasma haptoglobin and $\alpha 1$-acid glycoprotein after an 8 -week period, while only $\alpha 1$-acid glycoprotein was decreased with curcumin supplementation. The authors also investigated the effect of these supplements on the gene expression of numerous immune mediators. Citrus bioflavonoids decreased interferon gamma gene transcripts, while curcumin attenuated IL-2 expression. ${ }^{113}$

Overall, it is evident that we are in the infancy of understanding obesity and its health ramifications in dogs and cats; however, there are many areas of promise regarding supplementation and dietary manipulation. It is expected that this area of preventative medicine will continue to grow, as there have been a number of advances in dietary formulas and in patient and owner support to help mitigate weight loss. Most importantly, general practitioners are the front line in combating this ever-growing health problem, and if equipped with a better understanding of the physioenvironmental influences and psychosocial factors involved with each case, then implementation of diet plans that support the owner and the patient will likely lead to more successful treatment.

\section{Disclosure}

The authors report no conflicts of interest in this work.

\section{References}

1. Lund EM, Armstrong PJ, Kirk CA, Klausner JS. Prevalence and risk factors for obesity in adult cats from private US veterinary practices. Int J Appl Res Vet Med. 2005;3(2):88.

2. Lund EM, Armstrong PJ, Kirk CA, Klausner JS. Prevalence and risk factors for obesity in adult dogs from private US veterinary private practices. Int J Appl Res Vet Med. 2006;4(2):177.

3. Scarlett JM, Donoghue S. Associations between body condition and disease in cats. J Am Vet Med Assoc. 1998;212(11):1725-1731.

4. Speakman JR. Obesity: the integrated roles of environment and genetics. J Nutr. 2004;134(8 Suppl):2090S-2105S.

5. Speakman JR, Levitsky DA, Allison DB, et al. Set points, settling points and some alternative models: Theoretical options to understand how genes and environments combine to regulate body adiposity. Dis Model Mech. 2011;4(6):733-745.
6. Suzuki K, Simpson KA, Minnion JS, Shillito JC, Bloom SR. The role of gut hormones and the hypothalamus in appetite regulation. Endocr J. 2010;57(5):359-372.

7. Arora S, Anubhuti. Role of neuropeptides in appetite regulation and obesity - a review. Neuropeptides. 2006;40(6):375-401.

8. Schneeberger M, Gomis R, Claret M. Hypothalamic and brainstem neuronal circuits controlling homeostatic energy balance. J Endocrinol. 2014;220(2):T25-T46.

9. Nannipieri M, Baldi S, Mari A, et al. Roux-en-Y gastric bypass and sleeve gastrectomy: mechanisms of diabetes remission and role of gut hormones. J Clin Endocrinol Metab. 2013;98(11):4391-4399.

10. Neff KJ, O’Shea D, le Roux CW. Glucagon like peptide-1 (GLP-1) dynamics following bariatric surgery: a signpost to a new frontier. Curr Diabetes Rev. 2013;9(2):93-101.

11. Ramon JM, Salvans S, Crous X, et al. Effect of roux-en-Y gastric bypass vs sleeve gastrectomy on glucose and gut hormones: a prospective randomised trial. J Gastrointest Surg. 2012;16(6):1116-1122.

12. Holst JJ. Incretin hormones and the satiation signal. Int J Obes (Lond). 2013;37(9):1161-1168.

13. Marino AB, Cole SW, Nuzum DS. Alternative dosing strategies for liraglutide in patients with type 2 diabetes mellitus. Am J Health Syst Pharm. 2014;71(3):223-226.

14. Mason BL, Wang Q, Zigman JM. The central nervous system sites mediating the orexigenic actions of ghrelin. Annu Rev Physiol. 2014;76:519-533

15. Nass R. Growth hormone axis and aging. Endocrinol Metab Clin North Am. 2013;42(2):187-199.

16. Reano S, Graziani A, Filigheddu N. Acylated and unacylated ghrelin administration to blunt muscle wasting. Curr Opin Clin Nutr Metab Care. 2014;17(3):236-240.

17. Wren JA, King VL, Campbell SL, Hickman MA. Biologic activity of dirlotapide, a novel microsomal triglyceride transfer protein inhibitor, for weight loss in obese dogs. J Vet Pharmacol Ther. 2007;30 Suppl 1:33-42.

18. Coleman DL. Effects of parabiosis of obese with diabetes and normal mice. Diabetologia. 1973;9(4):294-298.

19. Tartaglia LA. The leptin receptor. J Biol Chem. 1997;272(10):6093-6096.

20. Zhang Y, Proenca R, Maffei M, Barone M, Leopold L, Friedman JM. Positional cloning of the mouse obese gene and its human homologue. Nature. 1994;372(6505):425-432.

21. Heymsfield SB, Greenberg AS, Fujioka K, et al. Recombinant leptin for weight loss in obese and lean adults: a randomized, controlled, dose-escalation trial. JAMA. 1999;282(16):1568-1575.

22. Grasso P. Novel approaches to the treatment of obesity and type 2 diabetes mellitus: bioactive leptin-related synthetic peptide analogs. Recent Pat Endocr Metab Immune Drug Discov. 2011;5(3):163-175.

23. Appleton DJ, Rand JS, Sunvold GD. Plasma leptin concentrations in cats: reference range, effect of weight gain and relationship with adiposity as measured by dual energy X-ray absorptiometry. J Feline Med Surg. 2000;2(4):191-199.

24. Radin MJ, Sharkey LC, Holycross BJ. Adipokines: a review of biological and analytical principles and an update in dogs, cats, and horses. Vet Clin Pathol. 2009;38(2):136-156.

25. German AJ, Ryan VH, German AC, Wood IS, Trayhurn P. Obesity, its associated disorders and the role of inflammatory adipokines in companion animals. Vet J. 2010;185(1):4-9.

26. Trayhurn P, Wood IS. Adipokines: inflammation and the pleiotropic role of white adipose tissue. Br J Nutr. 2004;92(3):347-355.

27. German AJ, Hervera M, Hunter L, et al. Improvement in insulin resistance and reduction in plasma inflammatory adipokines after weight loss in obese dogs. Domest Anim Endocrinol. 2009;37(4): 214-226.

28. Tvarijonaviciute A, Ceron JJ, Holden SL, et al. Obesity-related metabolic dysfunction in dogs: a comparison with human metabolic syndrome. BMC Vet Res. 2012;8:147.

29. Wakshlag JJ, Struble AM, Levine CB, Bushey JJ, Laflamme DP, Long GM. The effects of weight loss on adipokines and markers of inflammation in dogs. Br J Nutr. 2011;106 Suppl 1:S11-S14. 
30. Tvarijonaviciute A, Ceron JJ, Holden SL, Biourge V, Morris PJ, German AJ. Effect of weight loss in obese dogs on indicators of renal function or disease. J Vet Intern Med. 2013;27(1):31-38.

31. Devaraj S, Singh U, Jialal I. Human C-reactive protein and the metabolic syndrome. Curr Opin Lipidol. 2009;20(3):182-189.

32. Tvarijonaviciute A, Ceron JJ, Holden SL, Morris PJ, Biourge V, German AJ. Effects of weight loss in obese cats on biochemical analytes related to inflammation and glucose homeostasis. Domest Anim Endocrinol. 2012;42(3):129-141.

33. Ricci R, Bevilacqua F. The potential role of leptin and adiponectin in obesity: a comparative review. Vet J. 2012;191(3):292-298.

34. Linscheid P, Christ-Crain M, Stoeckli R, et al. Increase in high molecular weight adiponectin by bariatric surgery-induced weight loss. Diabetes Obes Metab. 2008;10(12):1266-1270.

35. Brunson BL, Zhong Q, Clarke KJ, et al. Serum concentrations of adiponectin and characterization of adiponectin protein complexes in dogs. Am J Vet Res. 2007;68(1):57-62.

36. Ishioka K, Omachi A, Sasaki N, Kimura K, Saito M. Feline adiponectin: molecular structures and plasma concentrations in obese cats. JVet Med Sci. 2009;71(2):189-194.

37. Verkest KR, Rose FJ, Fleeman LM, et al. Adiposity and adiponectin in dogs: investigation of causes of discrepant results between two studies. Domest Anim Endocrinol. 2011;41(1):35-41.

38. Verkest KR, Fleeman LM, Morton JM, Ishioka K, Rand JS. Compensation for obesity-induced insulin resistance in dogs: assessment of the effects of leptin, adiponectin, and glucagon-like peptide-1 using path analysis. Domest Anim Endocrinol. 2011;41(1):24-34.

39. Tvarijonaviciute A, Jaillardon L, Ceron JJ, Siliart B. Effects of thyroxin therapy on different analytes related to obesity and inflammation in dogs with hypothyroidism. Vet $J$. 2013;196(1):71-75.

40. Lusby AL, Kirk CA, Bartges JW. The role of key adipokines in obesity and insulin resistance in cats. J Am Vet Med Assoc. 2009;235(5): $518-522$.

41. Van de Velde H, Janssens GP, de Rooster H, et al. The cat as a model for human obesity: insights into depot-specific inflammation associated with feline obesity. Br J Nutr. 2013;110(7):1326-1335.

42. Tvarijonaviciute A, Martinez S, Gutierrez A, Ceron JJ, Tecles F. Serum acute phase proteins concentrations in dogs during experimentally short-term induced overweight. A preliminary study. Res Vet Sci. 2011;90(1):31-34.

42. Lefebvre SL, Yang M, Wang M, Elliott DA, Buff PR, Lund EM. Effect of age at gonadectomy on the probability of dogs becoming overweight. J Am Vet Med Assoc. 2013;243(2):236-243.

43. Courcier EA, Thomson RM, Mellor DJ, Yam PS. An epidemiological study of environmental factors associated with canine obesity. J Small Anim Pract. 2010;51(7):362-367.

44. Butterwick R. How fat is that cat? J Feline Med Surg. 2000;2(2):91-94.

45. Courcier EA, Mellor DJ, Pendlebury E, Evans C, Yam PS. An investigation into the epidemiology of feline obesity in Great Britain: results of a cross-sectional study of 47 companion animal practises. Vet Rec. 2012;171(22):560.

46. Klimentidis YC, Beasley TM, Lin HY, et al. Canaries in the coal mine: a cross-species analysis of the plurality of obesity epidemics. Proc Biol Sci. 2011;278(1712):1626-1632.

47. Colliard L, Ancel J, Benet JJ, Paragon BM, Blanchard G. Risk factors for obesity in dogs in France. J Nutr. 2006;136(7 Suppl):1951S-1954S.

48. Kienzle E, Bergler R, Mandernach A. A comparison of the feeding behavior and the human-animal relationship in owners of normal and obese dogs. J Nutr. 1998;128(12 Supp1):2779S-2782S.

49. Mason E. Obesity in pet dogs. Vet Rec. 1970;86(21):612-616.

50. Nijland ML, Stam F, Seidell JC. Overweight in dogs, but not in cats, is related to overweight in their owners. Public Health Nutr. 2010;13(1): 102-106.

51. Cave NJ, Allan FJ, Schokkenbroek SL, Metekohy CA, Pfeiffer DU. A cross-sectional study to compare changes in the prevalence and risk factors for feline obesity between 1993 and 2007 in New Zealand. Prev Vet Med. 2012;107(1-2):121-133.
52. Laflamme DP. Nutrition for aging cats and dogs and the importance of body condition. Vet Clin North Am Small Anim Pract. 2005;35(3): 713-742.

53. Corbee RJ. Obesity in show dogs. J Anim Physiol Anim Nutr (Berl). August 11, 2012. [Epub ahead of print.]

54. Laflamme DP. Understanding and managing obesity in dogs and cats. Vet Clin North Am Small Anim Pract. 2006;36(6):1283-1295, vii.

55. Laflamme DP. Development and validation of a body condition score system for dogs: a clinical tool. Canine Pract. 1997;22(10-5).

56. Laflamme DP. Development and validation of a body condition score system for cats: A clinical tool. Feline Pract. 1997;25(13-8).

57. Mawby DI, Bartges JW, d'Avignon A, Laflamme DP, Moyers TD, Cottrell T. Comparison of various methods for estimating body fat in dogs. J Am Anim Hosp Assoc. 2004;40(2):109-114.

58. National Research Council (US). Ad Hoc Committee on Dog and Cat Nutrition. Nutrient Requirements of Dogs and Cats. Washington, DC, USA: National Academies Press; 2006. Available from: http://www.loc. gov/catdir/toc/ecip065/2005037411.html. Accessed July 26, 2014.

59. Serisier S, Weber M, Feugier A, et al. Maintenance energy requirements in miniature colony dogs. J Anim Physiol Anim Nutr (Berl). 2013; 97 Suppl 1:60-67.

60. Hill RC. Challenges in measuring energy expenditure in companion animals: a clinician's perspective. J Nutr. 2006;136(Suppl 7): 1967S-1972S.

61. Center SA, Warner KL, Randolph JF, Sunvold GD, Vickers JR. Influence of dietary supplementation with (L)-carnitine on metabolic rate, fatty acid oxidation, body condition, and weight loss in overweight cats. Am J Vet Res. 2012;73(7):1002-1015.

62. Baldwin K, Bartges J, Buffington T, et al. AAHA nutritional assessment guidelines for dogs and cats. J Am Anim Hosp Assoc. 2010;46(4): 285-296.

63. World Small Animal Veterinary Association Nutritional Assessment Guidelines Task Force. 2011 nutritional assessment guidelines. J S Afr Vet Assoc. 2011;82(4):254-263.

64. Linder DE, Freeman LM, Morris P, et al. Theoretical evaluation of risk for nutritional deficiency with caloric restriction in $\operatorname{dogs}$. Vet $Q$. 2012;32(3-4):123-129.

65. Linder DE, Freeman LM, Holden SL, Biourge V, German AJ. Status of selected nutrients in obese dogs undergoing caloric restriction. BMC Vet Res. 2013;9:219.

66. Yaissle JE, Holloway C, Buffington CA. Evaluation of owner education as a component of obesity treatment programs for dogs. J Am Vet Med Assoc. 2004;224(12):1932-1935.

67. Wei A, Fascetti AJ, Villaverde C, Wong RK, Ramsey JJ. Effect of water content in a canned food on voluntary food intake and body weight in cats. Am J Vet Res. 2011;72(7):918-923.

68. Saker KE, Remillard RL. Performance of a canine weight-loss program in clinical practice. Vet Ther. 2005;6(4):291-302.

69. Wakshlag JJ, Struble AM, Warren BS, et al. Evaluation of dietary energy intake and physical activity in dogs undergoing a controlled weight-loss program. J Am Vet Med Assoc. 2012;240(4):413-419.

70. Michel K, Scherk M. From problem to success: feline weight loss programs that work. J Feline Med Surg. 2012;14(5):327-336.

71. Stefanick ML. Exercise and weight control. Exerc Sport Sci Rev. 1993;21:363-396.

72. Kushner RF, Blatner DJ, Jewell DE, Rudloff K. The PPET study: people and pets exercising together. Obesity (Silver Spring). 2006;14(10): $1762-1770$.

73. Cameron KM, Morris PJ, Hackett RM, Speakman JR. The effects of increasing water content to reduce the energy density of the diet on body mass changes following caloric restriction in domestic cats. J Anim Physiol Anim Nutr (Berl). 2011;95(3):399-408.

74. Nagaoka D, Mitsuhashi Y, Angell R, Bigley KE, Bauer JE. Re-induction of obese body weight occurs more rapidly and at lower caloric intake in beagles. J Anim Physiol Anim Nutr (Berl). 2010;94(3):287-292.

75. German AJ, Holden SL, Mather NJ, Morris PJ, Biourge V. Lowmaintenance energy requirements of obese dogs after weight loss. Br J Nutr. 2011;106 Suppl 1:S93-S96. 
76. Blanchard G, Nguyen P, Gayet C, Leriche I, Siliart B, Paragon BM. Rapid weight loss with a high-protein low-energy diet allows the recovery of ideal body composition and insulin sensitivity in obese dogs. $J$ Nutr. 2004;134(8 Suppl):2148S-2150S.

77. Ibrahim WH, Szabo J, Sunvold GD, Kelleher JK, Bruckner GG. Effect of dietary protein quality and fatty acid composition on plasma lipoprotein concentrations and hepatic triglyceride fatty acid synthesis in obese cats undergoing rapid weight loss. Am J Vet Res. 2000;61(5):566-572.

78. Layman DK, Evans E, Baum JI, Seyler J, Erickson DJ, Boileau RA. Dietary protein and exercise have additive effects on body composition during weight loss in adult women. J Nutr. 2005;135(8): 1903-1910.

79. Layman DK. Protein quantity and quality at levels above the RDA improves adult weight loss. J Am Coll Nutr. 2004;23(Suppl 6): 631S-636S

80. Nair KS, Halliday D, Garrow JS. Thermic response to isoenergetic protein, carbohydrate or fat meals in lean and obese subjects. Clin $\mathrm{Sci}$ (Lond). 1983;65(3):307-312.

81. Weber M, Bissot T, Servet E, Sergheraert R, Biourge V, German AJ. A high-protein, high-fiber diet designed for weight loss improves satiety in dogs. J Vet Intern Med. 2007;21(6):1203-1208.

82. Vester Boler BM, Faber TA, Bauer LL, et al. Acute satiety response of mammalian, avian and fish proteins in dogs. Br J Nutr. 2012;107(1): 146-154.

83. Catalan V, Gomez-Ambrosi J, Rodriguez A, Fruhbeck G. Adipose tissue immunity and cancer. Front Physiol. 2013;4:275.

84. Wu JH, Cahill LE, Mozaffarian D. Effect of fish oil on circulating adiponectin: a systematic review and meta-analysis of randomized controlled trials. J Clin Endocrinol Metab. 2013;98(6):2451-2459.

85. Titos E, Claria J. Omega-3-derived mediators counteract obesityinduced adipose tissue inflammation. Prostaglandins Other Lipid Mediat. 2013;107:77-84.

86. Puglisi MJ, Hasty AH, Saraswathi V. The role of adipose tissue in mediating the beneficial effects of dietary fish oil. $J$ Nutr Biochem. 2011;22(2):101-108.

87. Jewell DE, Toll PW, Azain MJ, Lewis RD, Edwards GL. Fiber but not conjugated linoleic acid influences adiposity in dogs. Vet Ther. 2006;7(2):78-85.

88. Bosch G, Verbrugghe A, Hesta M, et al. The effects of dietary fibre type on satiety-related hormones and voluntary food intake in dogs. Br J Nutr. 2009;102(2):318-325.

89. Massimino SP, McBurney MI, Field CJ, et al. Fermentable dietary fiber increases GLP-1 secretion and improves glucose homeostasis despite increased intestinal glucose transport capacity in healthy dogs. J Nutr. 1998;128(10):1786-1793.

90. Conterno L, Fava F, Viola R, Tuohy KM. Obesity and the gut microbiota: does up-regulating colonic fermentation protect against obesity and metabolic disease? Genes Nutr. 2011;6(3):241-260.

91. Turnbaugh PJ, Ley RE, Mahowald MA, Magrini V, Mardis ER, Gordon JI. An obesity-associated gut microbiome with increased capacity for energy harvest. Nature. 2006;444(7122):1027-1031.

92. So PW, Yu WS, Kuo YT, et al. Impact of resistant starch on body fat patterning and central appetite regulation. PLoS One. 2007;2(12):e1309.

93. Cope MB, Erdman JW Jr, Allison DB. The potential role of soyfoods in weight and adiposity reduction: an evidence-based review. Obes Rev. 2008;9(3):219-235.

94. Hwang JT, Park IJ, Shin JI, et al. Genistein, EGCG, and capsaicin inhibit adipocyte differentiation process via activating AMPactivated protein kinase. Biochem Biophys Res Commun. 2005; 338(2):694-699.

95. Aoyama T, Fukui K, Takamatsu K, Hashimoto Y, Yamamoto T. Soy protein isolate and its hydrolysate reduce body fat of dietary obese rats and genetically obese mice (yellow KK). Nutrition. 2000;16(5):349-354.
96. Naaz A, Yellayi S, Zakroczymski MA, et al. The soy isoflavone genistein decreases adipose deposition in mice. Endocrinology. 2003;144(8): 3315-3320.

97. Mezei O, Banz WJ, Steger RW, Peluso MR, Winters TA, Shay N. Soy isoflavones exert antidiabetic and hypolipidemic effects through the PPAR pathways in obese zucker rats and murine RAW 264.7 cells. J Nutr. 2003;133(5):1238-1243.

98. Cerundolo R, Michel KE, Court MH, et al. Effects of dietary soy isoflavones on health, steroidogenesis, and thyroid gland function in dogs. Am J Vet Res. 2009;70(3):353-360.

99. Cave NJ, Backus RC, Marks SL, Klasing KC. Oestradiol, but not genistein, inhibits the rise in food intake following gonadectomy in cats, but genistein is associated with an increase in lean body mass. J Anim Physiol Anim Nutr (Berl). 2007;91(9-10):400-410.

100. Cave NJ, Backus RC, Marks SL, Klasing KC. Oestradiol and genistein reduce food intake in male and female overweight cats after gonadectomy. N Z Vet J. 2007;55(3):113-119.

101. Pekala J, Patkowska-Sokola B, Bodkowski R, et al. L-carnitine metabolic functions and meaning in humans life. Curr Drug Metab. 2011;12(7):667-678.

102. Blanchard G, Paragon BM, Milliat F, Lutton C. Dietary L-carnitine supplementation in obese cats alters carnitine metabolism and decreases ketosis during fasting and induced hepatic lipidosis. J Nutr. 2002;132(2):204-210.

103. Center SA, Harte J, Watrous D, et al. The clinical and metabolic effects of rapid weight loss in obese pet cats and the influence of supplemental oral L-carnitine. J Vet Intern Med. 2000;14(6):598-608.

104. Broekhuysen J, Baudine A, Deltour G. Effect of carnitine on acidosis and ketosis induced by lipid perfusions in dogs during starvation. Biochim Biophys Acta. 1965;106(1):207-210.

105. Blanchard G, Paragon BM, Milliat F, Lutton C. Dietary L-carnitine supplementation in obese cats alters carnitine metabolism and decreases ketosis during fasting and induced hepatic lipidosis. J Nutr. 2002;132(2):204-210.

106. Kovacs EM, Mela DJ. Metabolically active functional food ingredients for weight control. Obes Rev. 2006;7(1):59-78.

107. Rothwell NJ, Stock MJ. Stimulation of thermogenesis and brown fat activity in rats fed medium chain triglyceride. Metabolism. 1987;36(2): $128-130$

108. Furuse M, Choi YH, Mabayo RT, Okumura J. Feeding behavior in rats fed diets containing medium chain triglyceride. Physiol Behav. 1992;52(4):815-817.

109. Lasekan JB, Rivera J, Hirvonen MD, Keesey RE, Ney DM. Energy expenditure in rats maintained with intravenous or intragastric infusion of total parenteral nutrition solutions containing medium- or long-chain triglyceride emulsions. J Nutr. 1992;122(7):1483-1492.

110. Studzinski CM, MacKay WA, Beckett TL, et al. Induction of ketosis may improve mitochondrial function and decrease steady-state amyloid-beta precursor protein (APP) levels in the aged dog. Brain Res. 2008;1226:209-217.

111. Hall JA, Jewell DE. Feeding healthy beagles medium-chain triglycerides, fish oil, and carnitine offsets age-related changes in serum fatty acids and carnitine metabolites. PLoS One. 2012;7(11):e49510.

112. Serisier S, Leray V, Poudroux W, Magot T, Ouguerram K, Nguyen P. Effects of green tea on insulin sensitivity, lipid profile and expression of PPARalpha and PPARgamma and their target genes in obese dogs. Br J Nutr. 2008;99(6):1208-1216.

113. Leray V, Freuchet B, Le Bloc'h J, Jeusette I, Torre C, Nguyen P. Effect of citrus polyphenol- and curcumin-supplemented diet on inflammatory state in obese cats. Br J Nutr. 2011;106 Suppl 1:S198-S201.

114. National Research Council. Nutrient Requirements of Dogs and Cats. Washington, DC: The National Academies Press, 2006. 
Veterinary Medicine: Research and Reports

Dovepress

\section{Publish your work in this journal}

Veterinary Medicine: Research and Reports is an international, Visit http://www.dovepress.com/testimonials.php to read real quotes peer-reviewed, open access journal publishing original research, from published authors.

case reports, editorials, reviews and commentaries on all areas of

veterinary medicine. The manuscript management system is completely online and includes a very quick and fair peer-review system.

Submit your manuscript here: http://www.dovepress.com/veterinary-medicine-research-and-reports-journal 